\title{
ARTIKELEN
}

\section{De duistere wereld van hondengevechten ${ }^{*}$}

\author{
Anton van Wijk, Nienke Endenburg, Daan van Uhm \& Dina Siegel
}

\section{Inleiding}

Het organiseren van hondengevechten is in Nederland verboden. Bij dergelijke gevechten moeten twee honden elkaar op leven en dood bevechten. Het dierenleed dat hierachter schuilgaat, is enorm. Opmerkelijk is dat er in Nederland weinig bekend is over het fenomeen hondengevechten, zowel in wetenschappelijk opzicht als door middel van strafrechtelijke zaken. Op dat laatste is vorig jaar een uitzondering gekomen. De rechtbank Amsterdam veroordeelt een verdachte voor het organiseren van hondengevechten. Uit de tenlastelegging van het Openbaar Ministerie (OM) blijkt dat het niet alleen om hondengevechten gaat, ook verdenkt het OM de verdachte van 'het (opzettelijk) fokken van honden op/met vechtkenmerken en/of met agressieve karaktereigenschappen; het (opzettelijk) verrichten van een lichamelijke ingreep bij een van de honden door de poot te hechten met een hechtpistool; het veroorzaken van pijn/letsel bij een dier of het benadelen van de gezondheid/welzijn van een dier; het (opzettelijk) in Nederland brengen, ontvangen, voorhanden hebben en/of in voorraad hebben van diergeneesmiddelen; het (opzettelijk) in voorraad hebben van en/of het binnen of buiten Nederlands grondgebied brengen van geneesmiddelen zonder de daarvoor vereiste vergunning; en tot slot het deelnemen aan een criminele organisatie gericht op onder andere het organiseren van hondengevechten en het fokken van vechthonden'. ${ }^{1}$ De rechtbank veroordeelt de verdachte tot een gevangenisstraf van acht maanden, waarvan drie maanden voorwaardelijk, met een proeftijd van drie jaar en met als bijzondere voorwaarde een verbod voor het houden van honden. Uit deze casus blijkt dat het laten vechten van honden niet op zichzelf staat, maar dat er sprake is van verschillende gedragingen die zijn verboden.

In deze bijdrage schetsen we de wereld die achter de hondengevechten schuilgaat door te beschrijven hoe de hondengevechten in hun werk gaan, wie deel uitmaken van de entourage en binnen welke criminele infrastructuur de hondengevechten zich afspelen. Bij wijze van beschouwing op de problematiek wordt ingegaan op de huidige aanpak door de geëigende instanties en welke lacunes daarin zijn te ontdekken.

* Dit artikel is gebaseerd op het onderzoek naar hoog-risicohonden, waarin ook aandacht is geweest voor hondengevechten: A. van Wijk e.a., Hoog-risico honden, een bijtend probleem? Een fenomeenonderzoek naar bijtincidenten en hondengevechten, Arnhem: Bureau Beke 2019. Het onderzoek is gefinancierd door de Koninklijke Hondenbescherming. 


\section{Honden in 'de ring'}

Waar vechtsporters elkaar treffen in de ring, staan de vechthonden in een zogenoemde pit, een met schotten ommuurde plek van 4 bij 4 meter en 60 centimeter hoog. ${ }^{2}$ Niet elke hond is geschikt om te laten vechten. In de volksmond heten ze vechthonden, neutraler geformuleerd zijn het hoog-risicohonden, omdat deze honden bij bijten in staat zijn tot het toebrengen van bovenmatig ernstige bijtschade (zoals verlies van spier- en/of orgaanweefsel), soms met de dood tot gevolg. ${ }^{3}$ Hierbij dient opgemerkt te worden dat niet iedere hoog-risicohond een vechthond is. Bij de beoordeling of een hond aangemerkt dient te worden als hoog-risicohond, wordt gekeken naar verschillende factoren. Deze factoren - fysieke verschijning, bijtstijl, bijtintensiteit en de genetische basis - zijn bepalend voor de kwalificatie hoog-risicohonden. ${ }^{4}$ Dat was althans in 2017 het geval toen het ministerie een lijst van 22 hondenrassen als hoog risico had aangemerkt. ${ }^{5}$ Inmiddels lijkt de discussie zich te verbreden: of een hond daadwerkelijk een hoog-risicohond is, hangt van meer af dan van het ras alleen; ook de wijze van opvoeding en situationele factoren dragen hieraan bij. ${ }^{6}$ Hoe dan ook, in de pit staan geen chihuahua's of labradors, maar meestal pitbull- en American staffordachtige honden. ${ }^{7}$

Vechthonden worden net als humane vechtsporters uitgebreid getraind om de winstkansen te vergroten. ${ }^{8}$ De belangrijkste eigenschap is hier gameness, ofwel de mate waarin een hond door wil vechten, ook als hij gewond is. De honden ondergaan een streng voedings- en trainingsschema. Om de kracht en het uithoudingsvermogen van de honden te trainen laten hondenvechters bijvoorbeeld de honden zich vastbijten in een opgehangen autoband of een brandweerslang om de kaakkracht te versterken, en laten ze de honden op een loopband lopen om het uithoudingsvermogen te vergroten. Dat gebeurt vaak's nachts om niet te worden gezien. Om deze eigenschappen extra te stimuleren krijgen de honden verschillende geneeskundige middelen toegediend, zoals anabolen steroïden, waardoor hun spieren sneller zullen groeien en hun kracht toeneemt. Het 'oefenen' met levende dieren, zoals katten en andere honden, vergroot de gameness.

Hondenvechters spreken af op welke geheime locatie het gevecht zal plaatsvinden. Deze locatie kan een loods op een afgelegen industrieterrein zijn, maar ook bij een hondenvechter thuis (bijvoorbeeld in de huiskamer, slaapkamer of garage), afhankelijk van de bereidheid van hondenvechters om gevechten bij hen thuis

2 Ook worden hondengevechten gehouden in de achterbak van een auto of op straat.

3 Kamerstuk 28286, nr. 909, bijlage 3.

4 Kamerstuk 28286, nr. 909, bijlage 3.

5 Kamerstuk 28286, nr. 909, bijlage 3.

6 J. Pluijmakers, J. Bowen \& J. Fatjo, The Safe Dog Project. Een onderzoeksproject naar de preventie van bijtincidenten, Maastricht: DAVALON 2019.

7 O. Yilmaz, 'Dog Fighting in Some European Countries', International Journal of Livestock Research 2016/12, p. 20-26, doi:10.5455/ijlr.20161204114048.

8 De informatie over de hondengevechten is voornamelijk gebaseerd op A. van Wijk e.a., Hoogrisico honden, een bijtend probleem? Een fenomeenonderzoek naar bijtincidenten en hondengevechten, Arnhem: Bureau Beke 2019. 
plaats te laten vinden. Enkele dagen voor het gevecht wordt de locatie voor het hondengevecht bekendgemaakt, veelal via social media. Toeschouwers betalen een entreegeld van rond de $€ 100$, maar ook hogere bedragen komen voor. De toeschouwers zijn vaak zelf ook hondenvechters. Er is een onafhankelijke scheidsrechter aanwezig, die het gevecht begeleidt en een deel van de opbrengst krijgt.

De duur van een hondengevecht varieert van enkele minuten tot ruim twee uur. Een gevecht eindigt als een hond of zijn baasje opgeeft, de hond is doodgebeten of de scheidsrechter een einde maakt aan de wedstrijd. Sommige gevechten worden door vechters of omstanders opgenomen of zelfs direct uitgezonden via social media om ze te delen met andere geïnteresseerden. Op deze wijze kunnen er ook digitaal weddenschappen worden afgesloten.

Het winnen van een gevecht levert status en titels op. Hoe meer titels, des te meer status. Als een hond een gevecht wint, zet de hondenvechter een ' $1 \mathrm{xW}$ ' naast zijn naam om aan te duiden dat deze hond een gevecht heeft gewonnen. Als een hond een gevecht verliest, zet een vechter ' $1 \mathrm{xLG}$ ' of ' $1 \mathrm{xL}$ ' naast de naam. Als een hond drie gevechten heeft gewonnen, kan de hond de letters ' $\mathrm{CH}$ ' oftewel 'champion' voor zijn naam dragen. Wint een hond vijf gevechten, dan is het een 'Gr CH': 'Grand champion'. De titel 'Register of Merit' is de meest prestigieuze titel voor afstammelingen van honden en geeft hondenvechters de meeste status. Er circuleren in de Verenigde Staten en Europa diverse platforms waarop de rankings staan vermeld. ${ }^{9}$

Een van de hoofdredenen voor het houden van een vechthond is status. De hond moet agressiviteit en dominantie uitstralen, eigenschappen waarmee de eigenaar zich wil identificeren. De vechthond als statussymbool. ${ }^{10}$ Een andere reden voor het organiseren van en meedoen aan hondengevechten is geld. De waarde van een hond in de vechtwereld wordt getaxeerd aan de hand van het aantal overwinningen. Hoe meer een hond wint, hoe meer de hond waard wordt en hoe interessanter het is om met de hond te fokken. Het gaat bij het fokken van succesvolle vechthonden voornamelijk om een goede bloedlijn. Een succesvolle vechthond vergroot de kans op even succesvolle nakomelingen, wat de prijs van deze nakomelingen kan verhogen. Zij kunnen hierdoor in hondengevechten veel geld opbrengen, uit internationaal onderzoek blijkt zelfs tot $\$ 750.000,{ }^{11}$ maar dit zijn hoge uitzonderingen. In Nederland is, blijkens in beslag genomen WhatsAppberichten, een champion een paar duizend euro waard. ${ }^{12}$ De prijzen voor puppy's van vechthonden variëren van enkele honderden tot een paar duizend euro. Het bedrag dat een puppy van vechthonden oplevert, is afhankelijk van de bloedlijn en het geslacht en van het land van herkomst. Bij honden uit goede bloedlijnen is de kans op geschikte puppy's voor hondengevechten groter, hetgeen de prijs ver-

9 Zie bijv. https://pedigree.gamedogs.cz/details.php?id=87574.

10 In diverse onderzoeken komt dit aspect van hond als statussymbool duidelijk naar voren. Bijv. A. Duijnker, De hond, statussymbool of bitcoin? Onderzoek naar de rol van honden binnen de (ondermijnende) criminaliteit, Apeldoorn: School voor Hogere Politiekunde 2016; S. Harding, Unleashed: The phenomena of status dogs and weapon dogs, Policy Press 2014.

11 S. Harding \& A. Nurse, Analysis of UK dog fighting, laws and offences, Londen: Middlesex University 2015.

12 Van Wijk e.a. 2019. 
hoogt. Ook vindt handel plaats in sperma van succesvolle vechthonden. De fokkers verkopen de honden aan handelaren.

\section{Entourage: fokkers, handelaren en vechters}

Bij de hondengevechten zijn, naast de scheidsrechter, drie partijen betrokken: fokkers, handelaren en vechters. ${ }^{13}$ De fokkers hebben als doel de perfecte vechthond te fokken. Daarvoor zijn bloedlijnen essentieel. Het fokken met afstammelingen van champions moet het genetische selectieproces sturen naar overwinningen en dus status en geld. Geneesmiddelen moeten dat proces versterken. De selectie gebeurt vooral op reuen die gevechten winnen. Aangezien normaal sociaal contact met andere honden vrijwel niet mogelijk is, worden in dat geval 'rapestands' gebruikt, omdat er anders geen dekking maar een gevecht plaatsvindt. Het fokken van vechthonden gebeurt met name in Oost-Europese landen. ${ }^{14}$

De handelaren brengen de puppy's met bestelbusjes vanuit de Oost-Europese landen naar Nederland. ${ }^{15}$ De koop komt tot stand via privéberichten (WhatsApp). De handelaren vervalsen zo nodig de identificatie- en inentingsdocumenten. Ze betalen voor puppy's uit landen als Bulgarije en Roemenië een bescheiden bedrag van 200-300 euro en verkopen de dieren voor 600-700 euro. Honden uit de Verenigde Staten met een vergelijkbare bloedlijn kunnen het tienvoudige opleveren.

De handelaren verkopen de honden ten slotte aan de hondenvechters. De literatuur verdeelt de vechters in drie categorieën: straatvechters, hobbyisten en professionals. ${ }^{16}$ De problematiek aangaande de eerste groep - de straatvechters wordt nogal eens geassocieerd met gangs. De hondengevechten ontstaan doorgaans spontaan, hebben een ongeorganiseerd karakter en zijn veelal gerelateerd aan drugs, geld of het vergroten van de reputatie van de eigenaar. In Nederland zijn dergelijke voorbeelden ook te vinden. ${ }^{17}$ Het betreft in die zaken vaak jonge mannen tussen de 14 en 25 jaar oud die ingebed zijn in de straatwereld. Deze hondenvechters hanteren eigen regels en zien hondengevechten voornamelijk als vermaak. Er gaat weinig tot geen geld in om. Slechts een aantal jongeren houdt honden voor gevechten voor plezier, voor geld en om schulden of geschillen te beslechten. De hondengevechten vinden plaats in verlaten gebouwen zoals garages of leegstaande panden, op verlaten terreinen of in openbare ruimtes zoals parken, die gemakkelijk toegankelijk zijn voor voetgangers, maar beperkte toegang bieden voor voertuigen. Straatvechters staan onderaan de ladder in de wereld van de hondengevechten. Het duurt lang om een hogere status te krijgen,

Van Wijk e.a. 2019.

Dit geldt overigens (met name ook) voor niet-vechthonden. De illegale handel in puppy's vanuit Oost-Europa is groot. Hierbij gaat het om zogenoemde boordfok (fokfabrieken), waar niet wordt gelet op genetische afstamming. Zie bijv. D.P. van Uhm, De puppydossiers. Onderzoek illegale hondenhandel, Den Haag: IFAW 2010; I. van Leidene.a., Zo ziek als een hond? Gezondheids- en socialisatieproblemen bij puppy's in Nederland in relatie tot de herkomst, Arnhem: Bureau Beke 2019.

Van Leiden e.a. 2019; Van Wijk e.a. 2019.

Zie o.a. Harding \& Nurse 2015; Yilmaz 2016.

Van Wijk e.a. 2019. 
omdat men veel respect, vertrouwen en aanzien in de scene moet verdienen alvorens te stijgen in rang.

De tweede categorie omvat de hobbyisten, die deelnemen aan gevechten als entertainment of ter aanvulling van hun inkomen. Zij hebben vaak één of meerdere honden die zij laten deelnemen in verschillende georganiseerde gevechten. Deze gevechten vinden plaats binnen een (geografisch) gesloten netwerk. ${ }^{18} \mathrm{Ze}$ zijn kleinschalig en worden bijvoorbeeld gehouden in rijtjeshuizen bij de hondenvechters thuis, waarbij hondenvechters elkaar goed kennen en vertrouwen. De casus uit de inleiding behoort tot deze categorie: de gevechten werden thuis, in de huiskamer gehouden. De huiselijke setting blijkt bijvoorbeeld uit een filmpje van een kamer waar een kindje van 1,5 of 2 jaar vanuit zijn kinderstoel zit toe te kijken. ${ }^{19}$ Om geen aandacht te trekken wordt tijdens een gevecht de radio of televisie aangezet, waardoor het geluid van de vechtende honden slecht te horen is van buitenaf. Door deze kleinschaligheid en 'ons-kent-ons'-mentaliteit nodigen hobbyisten weinig tot geen toeschouwers uit voor de gevechten. Deze categorie ziet hondengevechten als een sociale activiteit waarbij men meteen kan gokken; soms worden gevechten online gestreamd. De hobbyisten zijn geregeld betrokken bij bovenwereldevenementen, zoals hondenshows voor hoog-risicohonden en wedstrijden voor het trekken van gewichten. Zij zouden vaak afkomstig zijn uit een laag sociaaleconomisch milieu. De schaarse middelen gaan op aan de honden en hun training.

De derde categorie zijn de professionals, die vaak veel honden in hun bezit hebben en van het fokken en trainen van en het wedden op vechthonden hun beroep maken. Hun hondengevechten kennen een goed georganiseerd karakter en er gaan grote geldbedragen in om. Netwerken die op dit hoge niveau hondengevechten organiseren, opereren zowel nationaal als internationaal binnen besloten netwerken. Dit professionele en verborgen karakter maakt het voor overheidsinstanties moeilijk om zicht te krijgen op de hondengevechten en te interveniëren. ${ }^{20}$ Onderzoek in Nederland suggereert dat het veelal gaat om mannen van middelbare leeftijd. Volgens een goed ingewijde informant gaat het in Nederland om een tiental personen van Nederlandse, Turkse en Marokkaanse afkomst die in totaal 40-50 honden hebben om te vechten. ${ }^{21}$ Het totale aantal vechthonden in Nederland wordt geschat op $400 .{ }^{22}$ Het professionele aspect van deze hondengevechten wordt bevestigd door de toeschouwers en de weddenschappen die er plaatsvinden, waardoor het hondengevecht niet alleen lucratief wordt voor de hondenhouders, maar ook voor organisatoren, scheidsrechters en promotors. Dit kan resulteren in hondengevechten met veel belangstellenden. De professionals doorkruisen het land en laten hun honden ook in het buitenland vechten. Als ze niet deel-

19 Van Wijk e.a. 2019.

20 L. Kalof \& M.A. Iliopoulou, 'Abusing the human-animal bond: on the making of fighting dogs', in: The Psychology of the Human-Animal Bond, New York: Springer 2011, p. 321-332; R. Smith, 'Investigating financial aspects of dog-fighting in the UK', Journal of Financial Crime 2011/4, p. 336-346, doi.org/10.1108/13590791111173687.

21 Van Wijk e.a. 2019.

22 Van Wijk e.a. 2019. 
nemen aan de gevechten, zullen ze andere rollen vervullen (tegen betaling), bijvoorbeeld als scheidsrechter, organisator of promotor. Deze groep ziet haar activiteiten als 'sport', met een belangrijke geschiedenis van regels en afstamming van de 'sport'. Overigens geldt dat ook voor de andere categorieën hondenvechters. Als rechtvaardiging voor hun activiteiten stellen ze dat vechten het natuurlijke gedrag van deze honden is en dat ze uit 'liefde' hun honden gebruiken voor de sport. ${ }^{23}$

\section{Criminele sferen}

Hondenvechters laten, zoals gezegd, hun honden deelnemen aan gevechten om de status of het geld dat illegaal gokken op hondengevechten kan opleveren. ${ }^{24}$ Casuïstiek uit de Verenigde Staten laat zien dat er gewed wordt om bedragen variërend van 5000 tot 200.000 dollar. Het geld dat met een gevecht wordt verdiend, wordt vervolgens (opnieuw) geïnvesteerd in criminele activiteiten of regulier besteed. Het witwassen van de opbrengsten is dan ook een criminaliteitsvorm die uit hondengevechten voortvloeit. ${ }^{25}$ In Nederland zijn er geen aanwijzingen gevonden van een 'hondenmaffia' die hiërarchisch georganiseerd is. ${ }^{26}$ Het gaat om fluïde allianties die worden gevormd door verschillende (internationale) actoren. Ze komen bij elkaar (ook via social media of reguliere shows) en organiseren de hondengevechten. ${ }^{27}$ Wel komt uit onderzoek duidelijk naar voren dat (een deel van) de entourage nauw betrokken is bij andere criminele activiteiten, ${ }^{28}$ en het feit dat het internationaal georganiseerde groepen betreft, maakt dat het om een potentieel fors probleem kan gaan. Hondengevechten kunnen namelijk verbonden worden aan andere vormen van criminaliteit, in het bijzonder drugshandel. Diverse soorten harddrugs, waaronder cocaïne en heroïne, en softdrugs, zoals hennep, worden verhandeld buiten de gevechten om, maar ook tijdens gevechten vinden drugsdeals plaats. De relatie vechthonden en drugsmilieu blijkt ook uit het feit dat de honden worden ingezet voor beveiliging (van personen en bijvoorbeeld hennepplantages). De drugsgelden kunnen weer worden ingezet om hondengevechten te financieren of om mee te gokken. Vechthonden zijn eveneens een uitstekend wapen om anderen mee te bedreigen en intimideren, onder anderen de

23 Het onvermogen om honden als levende wezens te zien die pijn kunnen ervaren, ontgaat de entourage waarschijnlijk; iets wat ook pregnant uit een onderzoek naar dierenmishandelaars naar voren komt: A. van Wijk \& M. Hardeman, De aard van het beestje. Kenmerken en achtergronden van dierenmishandelaars (Politiekunde 86), Apeldoorn/Amsterdam: Politie en Wetenschap/ Reed Business.

24 Smith 2011; Kalof \& Iliopoulou 2011.

25 K. Strouse, Bad Newz: The Untold Story of the Michael Vick Dog Fighting Case, Charleston: Dog fighting Investigation Publications LLC 2009; Yilmaz 2016.

26 Van Wijk e.a. 2019.

27 Onderzoekers zijn aanwezig geweest bij dergelijke shows en hebben kunnen constateren dat het een internationaal gezelschap betrof (Van Wijk e.a. 2019), waar ze blijkens insiders ook de contacten leggen voor de organisaties van hondengevechten.

28 A. Duijnker, De Hond, Statussymbool of bitcoin? Onderzoek naar de rol van honden binnen de (ondermijnende) criminaliteit. Apeldoorn: School voor Hogere Politiekunde, 2016; Van Wijk e.a. 2019. 
handhavers die onderzoek (willen) doen naar hondengevechten, een fenomeen dat de politie niet vreemd is. Er kan in dat geval worden gesproken van status-and weapon dogs. ${ }^{29}$ De politie herkent uit de praktijk ook een nauwe relatie tussen motorbendes en vechthonden. De informatie over de criminele sferen waarin hondengevechten plaatsvinden, komt - bij gebrek aan systematisch onderzoek daarnaar - vooral van betrokken politiemensen die dergelijke signalen oppikken maar er weinig mee kunnen; daarover straks meer. Een bijkomend probleem is dat de wereld van hondengevechten erg gesloten is. Buitenstaanders vallen meteen op. Er gelden strenge toelatingsprocedures en beveiligings- en geheimhoudingscodes. Loyaliteit en toewijding aan de groep staan bovenaan. De mate waarin sprake is van andere vormen van criminaliteit zal afhangen van de betreffende categorie hondenvechters. Hoe die relaties er in de praktijk uitzien, is niet bekend en vergt nader wetenschappelijk en opsporingsonderzoek.

\section{Beschouwing: aanpak schiet tekort}

Georganiseerde hondengevechten zijn in Nederland bekend, maar niet in die mate dat de overheidsdiensten dit tot prioriteit verheffen. Het lijkt een geval van 'tussen servet en tafellaken'. In grote drugs-/motorbendezaken worden soms de vechthonden genoemd, maar vormen ze niet de kern van de zaak en strafbare gedragingen. Of er komen wel signalen door bij Meld Misdaad Anoniem of de dierenpolitie dat er op een adres hondengevechten plaatsvinden, maar dat leidt tot dusver niet tot een grootschalig onderzoek waar men doordringt tot internationale criminele vertakkingen. De zaak uit de inleiding is aan het rollen gekomen doordat een politiefunctionaris anoniem een filmpje van de hondengevechten kreeg doorgestuurd en er veel tijd en energie in heeft gestoken om dit tot een strafzaak te verheffen. Deze zaak is uniek, in die zin dat er normaliter geen tijd en capaciteit voor is. Problematischer is dat het fenomeen hondengevechten en de daarbij behorende criminele entourage eigenlijk nergens goed zijn ondergebracht in het fijnmazige strafrechtelijke netwerk van instanties, taken en bevoegdheden. Drugsonderzoeken en/of kennis over de criminele activiteiten van motorbendes brengen de link met vechthonden soms in beeld, maar dan vooral in de periferie. Het is letterlijk 'restinformatie'. En met restinformatie wordt over het algemeen te weinig gedaan. ${ }^{30}$

30 A. van Wijk \& L. Scholten, Onbenutte kansen. Een onderzoek naar het gebruik van restinformatie in de opsporing (Politiekunde 79), Apeldoorn/Amsterdam: Politie en Wetenschap/Reed Business 2016. 
Diergerelateerde zaken vallen ultimo onder de Milieukamer van het functioneel parket van het Openbaar Ministerie. ${ }^{31}$ De Milieukamer geeft aan de zaken rond hondengevechten niet tot haar taak te rekenen. De problematiek rond hondengevechten is weliswaar serieus, maar valt wat betreft de vervolging tussen wal en schip. De reden is dat hondengevechtzaken in de optiek van de Milieukamer geen milieuzaken zijn. De zaak die wel door de Milieukamer is gekomen, en dat is de zaak uit de inleiding, is een 'uitzondering'. Dit betekent dat er bij ongewijzigd beleid ten aanzien van de taken van de Milieukamer geen zaken betreffende hondengevechten worden opgepakt. ${ }^{32}$

Een meer filosofische vraag is of hondengevechten moeten worden aangemerkt als milieu-zaken waar mogelijk en begrijpelijk afwegingen moeten worden gemaakt tussen heel grote milieuzaken met asbest en illegale lozingen van gif en een signaal van hondengevechten. Dierenleed verliest het dan van milieuzaken. Als de samenleving honden als levende wezens beschouwt, waarom bestaat er dan een gelijkschakeling met asbest en is er sprake van een onderwaardering ten aanzien van bijvoorbeeld een klap die valt tussen twee dronken cafébezoekers? Dit moet anders worden ingericht.

De ietwat trieste slotsom is dat de strafrechtelijke aanpak van hondengevechten tot op heden geen groot succes is. Iedere kijker van hondengevechtfilmpjes op YouTube kan zich het dierenleed voorstellen dat inherent is aan hondengevechten. Honden die het gevecht verliezen, worden soms doodgeschoten en achteloos achtergelaten, of verzwaard met stenen in het water gegooid; ze worden ook wel gebruikt als oefenmateriaal voor andere vechthonden. Medewerkers van handhavings- en opsporingsdiensten als de Landelijke Inspectiedienst Dierenbescherming, de Nederlandse Voedsel- en Warenautoriteit en de dierenpolitie worden hier regelmatig mee geconfronteerd zonder dat het structureel kan worden opgepakt. De schaarse kennis over dit soort netwerken zou een 'ondermijningsbel' moeten laten rinkelen bij de instanties die gaan over prioritering. De kans voor de opsporingsdiensten (en prioritering door relevante gremia) is dat het organiseren en houden van hondengevechten een zeer nuttig aangrijpingspunt kan zijn om de criminele kluwen verder te ontrafelen. ${ }^{33}$ Dat vergt een andere kijk op opsporingsstrategieën en -technieken. Capaciteitskwesties mogen een gerichte aanpak van hondengevechten niet in de weg staan. Tegelijk geldt ook de regel: als je het niet wilt zien, is het er ook niet.

De wereld van hondengevechten is gelaagd. Een aangrijpingspunt voor een effectieve aanpak betreft de fok van de vechthonden, met name in Oost-Europese

31 Het functioneel parket is een specialistisch, landelijk opererend onderdeel van het Openbaar Ministerie dat zich toelegt op de bestrijding van complexe fraude en milieucriminaliteit en op het afwikkelen van complexe ontnemingszaken. Bij het uitvoeren van deze taken is het functioneel parket verantwoordelijk voor de opsporing en vervolging in strafzaken waarin een bijzondere opsporingsdienst (BOD) het opsporingsonderzoek doet, waaronder van de Nederlandse Voedselen Warenautoriteit (NVWA). Daarnaast is het functioneel parket verantwoordelijk voor de opsporing en vervolging van vrijwel alle milieuzaken van de Nationale Politie. Bron: www.om.nl/ organisatie/functioneel-parket.

32 Van Wijk e.a. 2019.

33 Een pleidooi van politiefunctionaris Dijncker 2016. 
landen, en de nagenoeg probleemloze export naar Nederland. Het vrije verkeer van personen en goederen binnen de Europese Unie is een zegen, maar tevens een vloek. Het feit dat illegale hondenhandelaren probleemloos de EU-grens passeren met illegale pups, verborgen in kratten in een bestelauto, en er vrijwel geen controles zijn, maakt dat de misstanden kunnen voortduren en er veel geld aan kan worden verdiend. De aanpak van de internationale, illegale puppyhandel vergt ook een internationale inzet van de betrokken landen. Nederland mag dan best het braafste jongetje van de klas zijn. 